\title{
Structure Controlling Factors of Oxido-Bridged Dinuclear Iron(III) Complexes
}

\author{
Ryusei Hoshikawa $^{1}$, Kosuke Yoshida $^{1}$, Ryoji Mitsuhashi ${ }^{2} \oplus$, Masahiro Mikuriya ${ }^{3} \oplus$, Takashi Okuno ${ }^{1}$ \\ and Hiroshi Sakiyama $1, *$ (D) \\ 1 Department of Science, Faculty of Science, Yamagata University, 1-4-12 Kojirakawa, \\ Yamagata 990-8560, Japan; hosiryu@yahoo.com (R.H.); thombrowne830@icloud.com (K.Y.); \\ okuno@sci.kj.yamagata-u.ac.jp (T.O.) \\ 2 Institute of Liberal Arts and Science, Kanazawa University, Kakuma, Kanazawa, Ishikawa 920-1192, Japan; \\ mitsuhashi@staff.kanazawa-u.ac.jp \\ 3 School of Science and Technology, Kwansei Gakuin University, 2-1 Gakuen, Sanda, Hyogo 669-1337, Japan; \\ junpei@kwansei.ac.jp \\ * Correspondence: saki@sci.kj.yamagata-u.ac.jp
}

check for updates

Citation: Hoshikawa, R.; Yoshida, K.; Mitsuhashi, R.; Mikuriya, M.; Okuno, T.; Sakiyama, H. Structure Controlling Factors of Oxido-Bridged Dinuclear Iron(III) Complexes. Molecules 2021, 26, 897. https://doi.org/10.3390/ molecules26040897

Academic Editor:

Catherine Housecroft

Received: 31 December 2020

Accepted: 2 February 2021

Published: 8 February 2021

Publisher's Note: MDPI stays neutral with regard to jurisdictional claims in published maps and institutional affiliations.

Copyright: (c) 2021 by the authors. Licensee MDPI, Basel, Switzerland. This article is an open access article distributed under the terms and conditions of the Creative Commons Attribution (CC BY) license (https:/ / creativecommons.org/licenses/by/ $4.0 /)$.

\begin{abstract}
Oxido bridges commonly form between iron(III) ions, but their bond angles and symmetry vary with the circumstances. A large number of oxido-bridged dinuclear iron(III) complexes have been structurally characterized. Some of them belong to the $C_{2}$ point group, possessing bent $\mathrm{Fe}-\mathrm{O}-\mathrm{Fe}$ bonds, while some others belong to the $C_{i}$ symmetry, possessing the linear Fe-OFe bonds. The question in this study is what determines the structures and symmetry of oxidobridged dinuclear iron(III) complexes. In order to gain further insights, three oxido-bridged dinuclear iron(III) complexes were newly prepared with 2,2'-bipyridine (bpy) and 1,10-phenanthroline (phen) ligands: $\left[\mathrm{Fe}_{2} \mathrm{OCl}_{2}(\mathrm{bpy})_{4}\right]\left[\mathrm{PF}_{6}\right]_{2}(\mathbf{1}),\left[\mathrm{Fe}_{2} \mathrm{O}\left(\mathrm{NO}_{3}\right)_{2}(\mathrm{bpy})_{4}\right]\left[\mathrm{PF}_{6}\right]_{2} \cdot 0.6 \mathrm{MeCN} \cdot 0.2(2-\mathrm{PrOH})(2)$, and $\left.\left[\mathrm{Fe}_{2} \mathrm{OCl}_{2} \text { (phen) }\right)_{4}\right]\left[\mathrm{PF}_{6}\right]_{2} \cdot \mathrm{MeCN} \cdot 0.5 \mathrm{H}_{2} \mathrm{O}$ (3). The crystal structures of $\mathbf{1}, \mathbf{2}$, and 3 were determined by the single-crystal $\mathrm{X}$-ray diffraction method, and all of them were found to have the bent $\mathrm{Fe}-\mathrm{O}-\mathrm{Fe}$ bonds. Judging from the crystal structure, some intramolecular interligand hydrogen bonds were found to play an important role in fixing the structures. Additional density functional theory (DFT) calculations were conducted, also for a related oxido-bridged dinuclear iron(III) complex with a linear $\mathrm{Fe}-\mathrm{O}-\mathrm{Fe}$ bond. We conclude that the $\mathrm{Fe}-\mathrm{O}-\mathrm{Fe}$ bridge tends to bend like a water molecule, but is often stretched by interligand steric repulsion, and that the structures are mainly controlled by the intramolecular interligand interactions.
\end{abstract}

Keywords: oxido-bridged dinuclear iron(III) complex; crystal structure; intramolecular interaction; magnetic properties; density functional theory (DFT)

\section{Introduction}

The iron(III)-oxido bond is easy to form, and the oxido ligand tends to bridge iron(III) ions. A typical example is a reddish-brown precipitation of hydroxidooxidoiron(III) by mixing the aqueous iron(III) nitrate solution and the sodium hydroxide solution at room temperature. The precipitation has been identified by X-ray diffraction [1] to have the same structure of the natural ore goethite, $\alpha-\mathrm{Fe}(\mathrm{O})(\mathrm{OH})$, in which iron(III) ions are bridged by the oxido and hydroxido ligands to form a polymeric structure [2]. The oxido-bridged dinuclear iron(III) motif is also often observed in various coordination compounds in biological systems. The oxy-form of hemerythrin has a ( $\mu$-oxido)bis( $\mu$-carboxylato)diiron(III) unit at the active site [3], and the two-electron-reduced dioxygen species (hydroperoxido ligand) is bound to one of the iron(III) ions and to the bridging oxido ligand. In another example, some ( $\mu$-oxido)diiron(III) complexes are known to cause characteristic renal injuries [4].

Various kinds of oxido-bridged dinuclear iron(III) complexes have been synthesized, and their structural and physicochemical properties have been studied [5-16]. In the case 
of symmetric dinuclear iron(III) complexes, some belong to the $C_{2}$ point group, possessing the twofold axis ( $C_{2}$ axis) through each oxido ligand, and some others belong to the $C_{i}$ point group, possessing the inversion center at each oxido ligand. From the magnetic point of view, the Dzyaloshinskii-Moriya interaction $[17,18]$ is expected for the $C_{2}$ symmetry, but not for the $C_{i}$ symmetry. Therefore, it is important to control the symmetry of metal complexes. In this study, three dinuclear iron(III) complexes were newly prepared with rigid 2,2'-bipyridine (bpy) and 1,10-phenanthroline (phen) ligands for the purpose of clarifying the factors in controlling the structures.

\section{Results and Discussion}

\subsection{Preparation of Complexes, 1,2 , and 3}

Three dinuclear iron(III) complexes, $\left[\mathrm{Fe}_{2} \mathrm{OCl}_{2}(\mathrm{bpy})_{4}\right]\left[\mathrm{PF}_{6}\right]_{2}(\mathbf{1}),\left[\mathrm{Fe}_{2} \mathrm{O}\left(\mathrm{NO}_{3}\right)_{2}(\mathrm{bpy})_{4}\right]$ $\left[\mathrm{PF}_{6}\right]_{2} \cdot 0.6 \mathrm{MeCN} \cdot 0.2(2-\mathrm{PrOH})(2)$, and $\left[\mathrm{Fe}_{2} \mathrm{OCl}_{2}(\mathrm{phen})_{4}\right]\left[\mathrm{PF}_{6}\right]_{2} \cdot \mathrm{MeCN} \cdot 0.5 \mathrm{H}_{2} \mathrm{O}(3)$, were newly prepared in this study. Complexes 1, 2, and 3 were all prepared in the dark to prevent photoreaction that results from the reduced species (e.g., $\left.\left[\mathrm{Fe}(\mathrm{bpy})_{3}\right]\left[\mathrm{PF}_{6}\right]_{2}[19]\right)$. In both IR spectra of $\mathbf{1}$ and $\mathbf{2}$ (Figures S1 and S2), the two strong bands were observed at around 1445 and $1600 \mathrm{~cm}^{-1}$ and were assigned to the ring stretching of the bpy moiety, where the corresponding bands were observed at around $1415-1455 \mathrm{~cm}^{-1}$ and $1560-1580 \mathrm{~cm}^{-1}$ for the free bpy ligand. On the other hand, for 3 (Figure S3), the strong bands at around 1425 and $1520 \mathrm{~cm}^{-1}$ were assigned to the ring stretching of the phen moiety, and the corresponding bands were observed at around 1410-1425 $\mathrm{cm}^{-1}$ and $1495-1505 \mathrm{~cm}^{-1}$ for the free phen ligand. Comparing the IR spectra of $\mathbf{1}$ and $\mathbf{2}$, the characteristic intense bands for $\mathbf{2}$ at around 1390 and $1280 \mathrm{~cm}^{-1}$ could be assigned to the monodentate nitrato ligand. The intense band at around $840 \mathrm{~cm}^{-1}$ common to complexes 1-3 was typical for the hexafluoridophosphate anion. All of the complexes were characterized by elemental analysis and a single-crystal X-ray diffraction study.

\subsection{Crystal Structures of Complexes, $\mathbf{1}, \mathbf{2}$, and $\mathbf{3}$}

\subsubsection{Crystal Structures of $\left[\mathrm{Fe}_{2} \mathrm{OCl}_{2}(\mathrm{bpy})_{4}\right]\left[\mathrm{PF}_{6}\right]_{2}(\mathbf{1})$}

The crystal of 1 consists of $\left[\mathrm{Fe}_{2} \mathrm{OCl}_{2}(\mathrm{bpy})_{4}\right]^{2+}$ complex cations and hexafluoridophosphate anions in a 1:2 molar ratio, and no solvent molecules are cocrystallized. The structure of the complex cation is depicted in Figure 1, and its selected bond distances and angles are summarized in Tables 1 and 2, respectively. The complex cation has a crystallographic twofold axis going through the oxido ligand, bridging the two iron(III) ions. Each iron(III) ion is coordinated by two bipyridine ligands, one chloride ligand, and the one oxido ligand, forming a distorted octahedral $\mathrm{ClN}_{4} \mathrm{O}$ coordination geometry. The average bond angle around the iron(III) ions was $89.7^{\circ}$ for the cis-positions, with a standard deviation of $8.9^{\circ}$. The crystal structure of the same complex cation was earlier reported as perchlorate salt, $\left[\mathrm{Fe}_{2} \mathrm{OCl}_{2}(\mathrm{bpy})_{4}\right]\left[\mathrm{ClO}_{4}\right]_{2} \cdot 0.25 \mathrm{MeCN} \cdot 0.25 \mathrm{MeOH} \cdot 0.25 \mathrm{H}_{2} \mathrm{O}(4)[6]$, and the bond distances and angles around the central iron(III) ions were very similar to each other.

Table 1. Selected distances for 1.

\begin{tabular}{cccc}
\hline Atom-Atom $^{\mathbf{1}}$ & Distance/A & Atom-Atom & Distance/ \\
\hline $\mathrm{Fe}(1)-\mathrm{Cl}(1)$ & $2.3119(5)$ & $\mathrm{Fe}(1)-\mathrm{O}(1)$ & $1.7819(3)$ \\
$\mathrm{Fe}(1)-\mathrm{N}(1)$ & $2.2169(15)$ & $\mathrm{Fe}(1)-\mathrm{N}(2)$ & $2.1446(15)$ \\
$\mathrm{Fe}(1)-\mathrm{N}(3)$ & $2.2279(15)$ & $\mathrm{Fe}(1)-\mathrm{N}(4)$ & $2.1357(15)$ \\
$\mathrm{Fe}(1) \cdots \mathrm{Fe}(1)^{\prime}$ & $3.5407(5)$ & & \\
\hline
\end{tabular}

${ }^{1}$ Symmetry code: ' $(1-x, y, 3 / 2-z)$. 


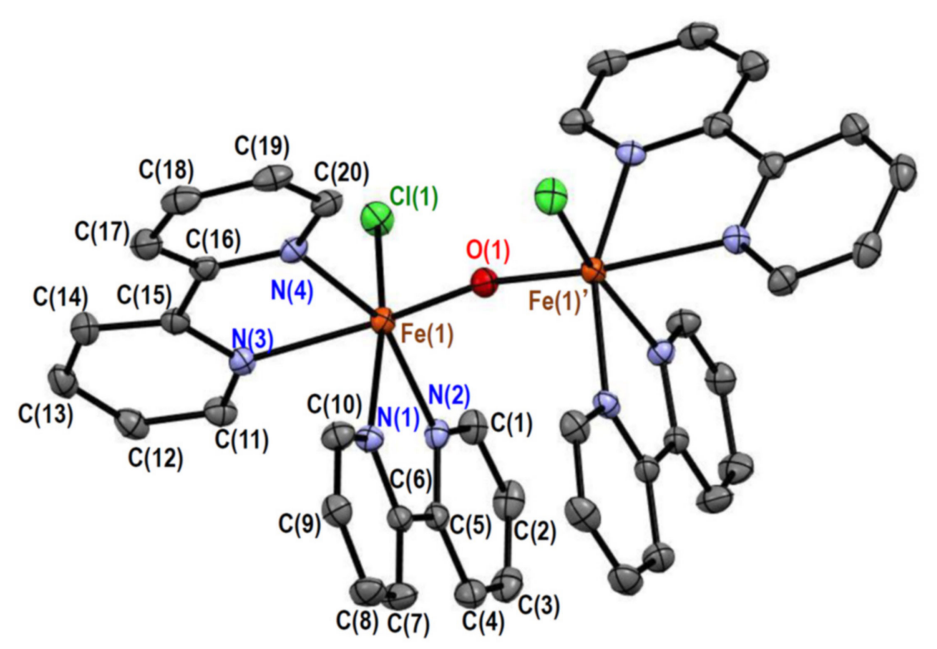

Figure 1. Crystal structure of $\left[\mathrm{Fe}_{2} \mathrm{OCl}_{2}(\mathrm{bpy})_{4}\right]^{2+}$ in 1. Hydrogen atoms are omitted for clarity. Symmetry code: ' $(1-x, y, 3 / 2-z)$.

Table 2. Selected angles for 1 .

\begin{tabular}{cccc}
\hline Atom-Atom-Atom & Angle $^{\circ}$ & Atom-Atom-Atom $^{\circ}$ & Angle/ $^{\circ}$ \\
\hline $\mathrm{Cl}(1)-\mathrm{Fe}(1)-\mathrm{O}(1)$ & $99.35(4)$ & $\mathrm{Cl}(1)-\mathrm{Fe}(1)-\mathrm{N}(1)$ & $166.69(4)$ \\
$\mathrm{Cl}(1)-\mathrm{Fe}(1)-\mathrm{N}(2)$ & $97.75(4)$ & $\mathrm{Cl}(1)-\mathrm{Fe}(1)-\mathrm{N}(3)$ & $86.33(4)$ \\
$\mathrm{Cl}(1)-\mathrm{Fe}(1)-\mathrm{N}(4)$ & $97.71(4)$ & $\mathrm{O}(1)-\mathrm{Fe}(1)-\mathrm{N}(1)$ & $92.71(5)$ \\
$\mathrm{O}(1)-\mathrm{Fe}(1)-\mathrm{N}(2)$ & $99.01(6)$ & $\mathrm{O}(1)-\mathrm{Fe}(1)-\mathrm{N}(3)$ & $168.39(5)$ \\
$\mathrm{O}(1)-\mathrm{Fe}(1)-\mathrm{N}(4)$ & $94.71(6)$ & $\mathrm{N}(1)-\mathrm{Fe}(1)-\mathrm{N}(2)$ & $74.65(6)$ \\
$\mathrm{N}(1)-\mathrm{Fe}(1)-\mathrm{N}(3)$ & $82.83(5)$ & $\mathrm{N}(1)-\mathrm{Fe}(1)-\mathrm{N}(4)$ & $86.81(6)$ \\
$\mathrm{N}(2)-\mathrm{Fe}(1)-\mathrm{N}(3)$ & $90.17(5)$ & $\mathrm{N}(2)-\mathrm{Fe}(1)-\mathrm{N}(4)$ & $157.33(6)$ \\
$\mathrm{N}(3)-\mathrm{Fe}(1)-\mathrm{N}(4)$ & $74.40(6)$ & $\mathrm{Fe}(1)-\mathrm{O}(1)-\mathrm{Fe}(1)^{\prime}$ & $166.95(11)$ \\
\hline
\end{tabular}

Symmetry code: ${ }^{\prime}(1-x, y, 3 / 2-z)$.

In complex 1 (Figure 1), two bpy moieties, bound to different iron(III) ions, look stacked; however, no attractive interaction is expected because the average separation [3.595(2) $\AA$ ] was larger than the sum of the van der Waals radius of two carbon atoms (3.4 $\AA$ ). On the contrary, an intramolecular $\mathrm{CH} \cdots \mathrm{O}$ hydrogen bond was observed between a bpy moiety and the bridging oxido ligand. Both the $\mathrm{C}(20) \cdots \mathrm{O}(1)[3.043(2) \AA]$ and $\mathrm{H}(20) \cdots \mathrm{O}(1)$ $(\sim 2.55 \AA)$ distances were shorter than the sum of the corresponding van der Waals radii, 3.22 and $2.61 \AA$, respectively. In addition, an intramolecular $\mathrm{CH}$... Cl hydrogen bond was observed, judging from the $\mathrm{Cl}(1) \cdots \mathrm{H}(20)^{\prime}$ distance $(\sim 2.62 \AA)$, shorter than the sum of the van der Waals radii $(2.84 \AA)$.

\subsubsection{Crystal Structures of $\left[\mathrm{Fe}_{2} \mathrm{O}\left(\mathrm{NO}_{3}\right)_{2}(\mathrm{bpy})_{4}\right]\left[\mathrm{PF}_{6}\right]_{2} \cdot 0.6 \mathrm{MeCN} \cdot 0.2(2-\mathrm{PrOH})(2)$}

The crystal of 2 consists of $\left[\mathrm{Fe}_{2} \mathrm{O}\left(\mathrm{NO}_{3}\right)_{2}(\mathrm{bpy})_{4}\right]^{2+}$ complex cations, hexafluoridophosphate anions, acetonitrile molecules, and 2-propanol molecules in a 1:2:0.6:0.2 molar ratio. The structure of the complex cation is depicted in Figure 2, and its selected bond distances and angles are summarized in Tables 3 and 4, respectively. The complex cation has a pseudo-twofold axis going through the oxido ligand, bridging the two iron(III) ions. Each iron(III) ion is coordinated by two bipyridine ligands, one monodentate nitrato ligand, and the one oxido ligand, forming a distorted octahedral $\mathrm{N}_{4} \mathrm{O}_{2}$ coordination geometry. The average bond angle around the iron(III) ions was $89.6^{\circ}$ for the cis-positions, with a standard deviation of $9.5^{\circ}$, which was slightly larger than that of 1 . This indicates that the octahedral coordination geometry of $\mathbf{2}$ is slightly more distorted than that of $\mathbf{1}$. Although the crystal structures of the chlorido derivative (4) and the sulfato derivative, $\left[\mathrm{Fe}_{2} \mathrm{O}\left(\mathrm{SO}_{4}\right)_{2}(\mathrm{bpy})_{4}\right] \cdot 11 \mathrm{H}_{2} \mathrm{O}(5)[10]$, have been reported, the structure of the nitrato derivative seems to be new. The bond distances and angles around the central iron(III) ions in 2 were not so different from those of the derivatives 1,4 , and 5 . The average bond angle 
around the iron(III) ions in 5 was $89.8^{\circ}$ for the cis-positions, with a standard deviation of $9.1^{\circ}$, indicating that the coordination geometries are more distorted with the larger nitrato and sulfato ligands than with the smaller chloride ligand.

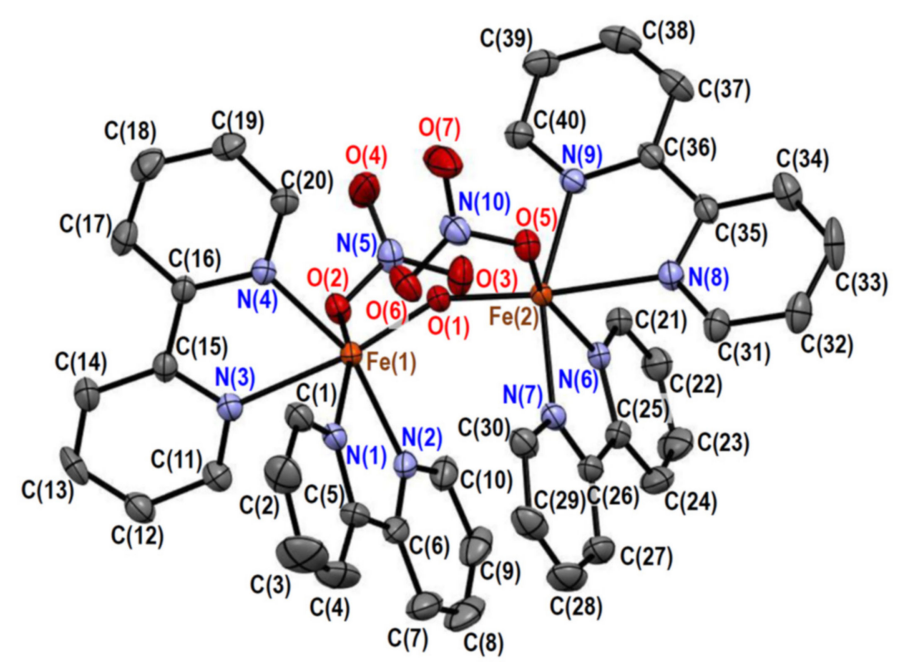

Figure 2. Crystal structure of $\left[\mathrm{Fe}_{2} \mathrm{O}\left(\mathrm{NO}_{3}\right)_{2}(\mathrm{bpy})_{4}\right]^{2+}$ in 2 . Hydrogen atoms are omitted for clarity.

Table 3. Selected distances for 2.

\begin{tabular}{cccc}
\hline Atom-Atom & Distance/ $\mathbf{A}$ & Atom-Atom & Distance/ \\
\hline $\mathrm{Fe}(1)-\mathrm{O}(1)$ & $1.792(19)$ & $\mathrm{Fe}(1)-\mathrm{O}(2)$ & $2.028(2)$ \\
$\mathrm{Fe}(1)-\mathrm{N}(1)$ & $2.167(2)$ & $\mathrm{Fe}(1)-\mathrm{N}(2)$ & $2.135(3)$ \\
$\mathrm{Fe}(1)-\mathrm{N}(3)$ & $2.247(2)$ & $\mathrm{Fe}(1)-\mathrm{N}(4)$ & $2.131(2)$ \\
$\mathrm{Fe}(2)-\mathrm{O}(1)$ & $1.791(19)$ & $\mathrm{Fe}(2)-\mathrm{O}(5)$ & $2.021(2)$ \\
$\mathrm{Fe}(2)-\mathrm{N}(6)$ & $2.166(2)$ & $\mathrm{Fe}(2)-\mathrm{N}(7)$ & $2.128(2)$ \\
$\mathrm{Fe}(2)-\mathrm{N}(8)$ & $2.228(2)$ & $\mathrm{Fe}(2)-\mathrm{N}(9)$ & $2.120(2)$ \\
$\mathrm{Fe}(1) \cdots \mathrm{Fe}(2)$ & $3.4729(5)$ & & \\
\hline
\end{tabular}

Table 4. Selected angles for 2.

\begin{tabular}{cccc}
\hline Atom-Atom-Atom & Angle $^{\circ}$ & Atom-Atom-Atom & Angle/ $^{\circ}$ \\
\hline $\mathrm{O}(1)-\mathrm{Fe}(1)-\mathrm{O}(2)$ & $99.96(9)$ & $\mathrm{O}(1)-\mathrm{Fe}(1)-\mathrm{N}(1)$ & $101.14(10)$ \\
$\mathrm{O}(1)-\mathrm{Fe}(1)-\mathrm{N}(2)$ & $100.97(9)$ & $\mathrm{O}(1)-\mathrm{Fe}(1)-\mathrm{N}(3)$ & $170.72(9)$ \\
$\mathrm{O}(1)-\mathrm{Fe}(1)-\mathrm{N}(4)$ & $96.46(9)$ & $\mathrm{O}(2)-\mathrm{Fe}(1)-\mathrm{N}(1)$ & $158.06(9)$ \\
$\mathrm{O}(2)-\mathrm{Fe}(1)-\mathrm{N}(2)$ & $94.65(10)$ & $\mathrm{O}(2)-\mathrm{Fe}(1)-\mathrm{N}(3)$ & $80.20(9)$ \\
$\mathrm{O}(2)-\mathrm{Fe}(1)-\mathrm{N}(4)$ & $91.38(9)$ & $\mathrm{N}(1)-\mathrm{Fe}(1)-\mathrm{N}(2)$ & $75.51(10)$ \\
$\mathrm{N}(1)-\mathrm{Fe}(1)-\mathrm{N}(3)$ & $79.94(9)$ & $\mathrm{N}(1)-\mathrm{Fe}(1)-\mathrm{N}(4)$ & $92.15(9)$ \\
$\mathrm{N}(2)-\mathrm{Fe}(1)-\mathrm{N}(3)$ & $88.24(9)$ & $\mathrm{N}(2)-\mathrm{Fe}(1)-\mathrm{N}(4)$ & $160.25(9)$ \\
$\mathrm{N}(3)-\mathrm{Fe}(1)-\mathrm{N}(4)$ & $74.27(9)$ & $\mathrm{O}(1)-\mathrm{Fe}(2)-\mathrm{O}(5)$ & $101.38(9)$ \\
$\mathrm{O}(1)-\mathrm{Fe}(2)-\mathrm{N}(6)$ & $98.66(9)$ & $\mathrm{O}(1)-\mathrm{Fe}(2)-\mathrm{N}(7)$ & $98.77(9)$ \\
$\mathrm{O}(1)-\mathrm{Fe}(2)-\mathrm{N}(8)$ & $172.76(9)$ & $\mathrm{O}(1)-\mathrm{Fe}(2)-\mathrm{N}(9)$ & $98.07(9)$ \\
$\mathrm{O}(5)-\mathrm{Fe}(2)-\mathrm{N}(6)$ & $159.31(9)$ & $\mathrm{O}(5)-\mathrm{Fe}(2)-\mathrm{N}(7)$ & $95.86(9)$ \\
$\mathrm{O}(5)-\mathrm{Fe}(2)-\mathrm{N}(8)$ & $80.12(9)$ & $\mathrm{O}(5)-\mathrm{Fe}(2)-\mathrm{N}(9)$ & $92.21(9)$ \\
$\mathrm{N}(6)-\mathrm{Fe}(2)-\mathrm{N}(7)$ & $75.94(9)$ & $\mathrm{N}(6)-\mathrm{Fe}(2)-\mathrm{N}(8)$ & $80.64(9)$ \\
$\mathrm{N}(6)-\mathrm{Fe}(2)-\mathrm{N}(9)$ & $90.02(9)$ & $\mathrm{N}(7)-\mathrm{Fe}(2)-\mathrm{N}(8)$ & $88.07(9)$ \\
$\mathrm{N}(7)-\mathrm{Fe}(2)-\mathrm{N}(9)$ & $159.49(9)$ & $\mathrm{N}(8)-\mathrm{Fe}(2)-\mathrm{N}(9)$ & $74.75(9)$ \\
$\mathrm{Fe}(1)-\mathrm{O}(1)-\mathrm{Fe}(2)$ & $151.44(12)$ & & \\
\hline
\end{tabular}

In complex 2 (Figure 2 ), a $\pi-\pi$ stacking was observed between two bpy moieties, which was evidenced by the average plane separation [3.351(4) $\AA$ ] shorter than the $C \cdots C$ van der Waals distance (3.4 $\AA$ ). Like in 1, an intramolecular $\mathrm{CH} \cdots$ O hydrogen bond was observed between a bpy moiety and the bridging oxido ligand. The $\mathrm{C}(20) \cdots \mathrm{O}(1)[3.107(3) \AA]$ and 
$\mathrm{C}(40) \cdots \mathrm{O}(1)[3.107(3) \AA]$ distances were shorter than the $\mathrm{C} \cdots \mathrm{O}$ van der Waals distances $(3.22 \AA)$, and the $\mathrm{H}(20) \cdots \mathrm{O}(1)(2.58 \AA)$ and $\mathrm{H}(40) \cdots \mathrm{O}(1)(2.58 \AA)$ distances were shorter than the $\mathrm{H} \cdots \mathrm{O}$ van der Waals distances $(2.61 \AA)$. In 2 , another attractive interaction was the $\mathrm{CH} \cdots \mathrm{O}$ hydrogen bond between the bpy and nitrato moieties. The $\mathrm{H} \cdots \mathrm{O}$ distances $[\mathrm{H}(10) \cdots \mathrm{O}(3): 2.50 \AA ; \mathrm{H}(30) \cdots \mathrm{O}(6): 2.52 \AA]$ were shorter than the $\mathrm{H} \cdots \mathrm{O}$ van der Waals distance $(2.61 \AA)$.

\subsubsection{Crystal Structures of $\left.\left[\mathrm{Fe}_{2} \mathrm{OCl}_{2} \text { (phen }\right)_{4}\right]\left[\mathrm{PF}_{6}\right]_{2} \cdot \mathrm{MeCN} \cdot 0.5 \mathrm{H}_{2} \mathrm{O}$ (3)}

The crystal of 3 consists of $\left.\left[\mathrm{Fe}_{2} \mathrm{OCl}_{2} \text { (phen) }\right)_{4}\right]^{2+}$ complex cations, hexafluoridophosphate anions, acetonitrile molecules, and water molecules in a 1:2:1:0.5 molar ratio. The structure of the complex cation is depicted in Figure 3, and its selected bond distances and angles are summarized in Tables 5 and 6, respectively. The complex cation has a pseudotwofold axis going through the oxido ligand, bridging the two iron(III) ions. Each iron(III) ion is coordinated by two phenanthroline ligands, one chloride ligand, and the one oxido ligand, forming a distorted octahedral $\mathrm{ClN}_{4} \mathrm{O}$ coordination geometry. The average bond angle around the iron(III) ions was $89.7^{\circ}$ for the cis-positions, with a standard deviation of $8.5^{\circ}$, which was comparable to that of $\mathbf{1}$, but slightly smaller. This indicates that the distortion of the octahedral coordination geometry of $\mathbf{3}$ is slightly smaller than that of $\mathbf{1}$. A crystal structure of an aqua derivative was earlier reported as $\left[\mathrm{Fe}_{2} \mathrm{O}\left(\mathrm{H}_{2} \mathrm{O}\right)_{2}(\mathrm{bpy})_{4}\right]\left[\mathrm{NO}_{3}\right]_{4} \cdot 5 \mathrm{H}_{2} \mathrm{O}$ (6) [13], in which chloride ligands were replaced with aqua ligands. The average $\mathrm{Fe}-\mathrm{N}$ distance at the cis-positions of the oxido ligand was $\sim 2.17 \AA$ for 3 , which was slightly longer than that for $6(\sim 2.15 \AA)$, and this is considered to be typical of the high-spin state [13]. From this point of view, the iron(III) ions in both $\mathbf{1}(\sim 2.17 \AA)$ and $\mathbf{2}(\sim 2.14 \AA)$ are considered to be in the high-spin state.

In complex 3 (Figure 3), a $\pi-\pi$ stacking was observed between two phen moieties. Although the average plane separation [3.415(5) $\AA$ ] was comparable to the C ...C van der Waals distance (3.4 $\AA$ ), short C...C distances [e.g., $C(17) \cdots C(39)=3.331(5) \AA$ ] were observed. Like in $\mathbf{1}$ and 2, an intramolecular $\mathrm{CH}$... O hydrogen bond was observed between a phen moiety and the bridging oxido ligand. The $\mathrm{C}(10) \cdots \mathrm{O}(1)[3.140(5) \AA]$ and $\mathrm{C}(34) \cdots \mathrm{O}(1)$ [3.072(4) $\AA$ ] distances were shorter than the $\mathrm{C}$... O van der Waals distance $(3.22 \AA)$. In 3 , the $\mathrm{CH} \cdots \mathrm{Cl}$ hydrogen bond between the phen and chlorido moieties did not seem to be strong.

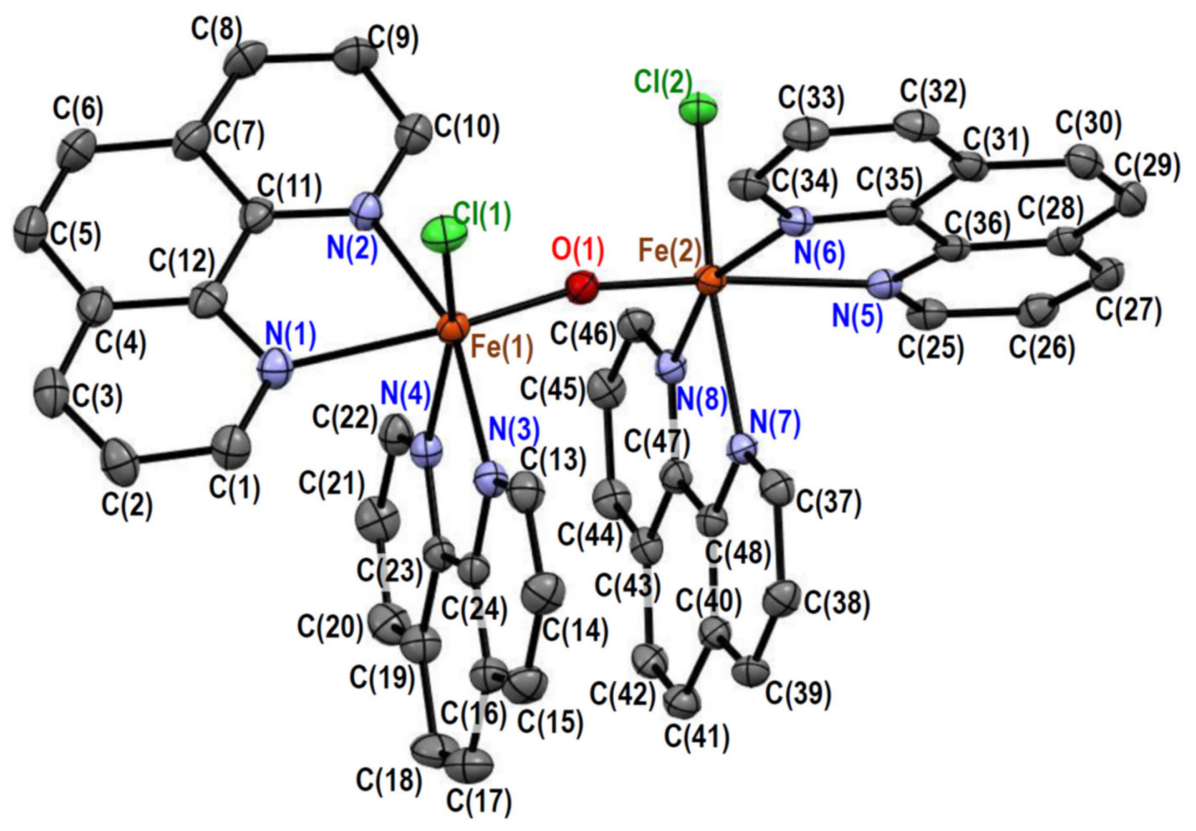

Figure 3. Crystal structure of $\left.\left[\mathrm{Fe}_{2} \mathrm{OCl}_{2} \text { (phen }\right)_{4}\right]^{2+}$ in 3 . Hydrogen atoms are omitted for clarity. 
Table 5. Selected distances for 3.

\begin{tabular}{|c|c|c|c|}
\hline Atom-Atom & Distance/Å & Atom-Atom & Distance/Å \\
\hline $\mathrm{Fe}(1)-\mathrm{Cl}(1)$ & $2.3315(10)$ & $\mathrm{Fe}(1)-\mathrm{O}(1)$ & $1.791(2)$ \\
\hline $\mathrm{Fe}(1)-\mathrm{N}(1)$ & $2.246(3)$ & $\mathrm{Fe}(1)-\mathrm{N}(2)$ & $2.134(3)$ \\
\hline $\mathrm{Fe}(1)-\mathrm{N}(3)$ & $2.156(3)$ & $\mathrm{Fe}(1)-\mathrm{N}(4)$ & $2.192(3)$ \\
\hline $\mathrm{Fe}(2)-\mathrm{Cl}(2)$ & $2.297(10)$ & $\mathrm{Fe}(2)-\mathrm{O}(1)$ & $1.786(2)$ \\
\hline $\mathrm{Fe}(2)-\mathrm{N}(5)$ & $2.283(3)$ & $\mathrm{Fe}(2)-\mathrm{N}(6)$ & $2.137(3)$ \\
\hline $\mathrm{Fe}(2)-\mathrm{N}(7)$ & $2.212(3)$ & $\mathrm{Fe}(2)-\mathrm{N}(8)$ & $2.165(3)$ \\
\hline $\mathrm{Fe}(1) \cdots \mathrm{Fe}(2)$ & $3.5501(7)$ & & \\
\hline
\end{tabular}

Table 6. Selected angles for 3 .

\begin{tabular}{cccc}
\hline Atom-Atom-Atom & Angle $^{\circ}$ & Atom-Atom-Atom & Angle $^{\circ}$ \\
\hline $\mathrm{Cl}(1)-\mathrm{Fe}(1)-\mathrm{O}(1)$ & $100.59(8)$ & $\mathrm{Cl}(1)-\mathrm{Fe}(1)-\mathrm{N}(1)$ & $88.26(7)$ \\
$\mathrm{Cl}(1)-\mathrm{Fe}(1)-\mathrm{N}(2)$ & $93.74(8)$ & $\mathrm{Cl}(1)-\mathrm{Fe}(1)-\mathrm{N}(3)$ & $94.93(8)$ \\
$\mathrm{Cl}(1)-\mathrm{Fe}(1)-\mathrm{N}(4)$ & $167.13(8)$ & $\mathrm{O}(1)-\mathrm{Fe}(1)-\mathrm{N}(1)$ & $167.95(11)$ \\
$\mathrm{O}(1)-\mathrm{Fe}(1)-\mathrm{N}(2)$ & $95.65(11)$ & $\mathrm{O}(1)-\mathrm{Fe}(1)-\mathrm{N}(3)$ & $98.64(11)$ \\
$\mathrm{O}(1)-\mathrm{Fe}(1)-\mathrm{N}(4)$ & $90.06(10)$ & $\mathrm{N}(1)-\mathrm{Fe}(1)-\mathrm{N}(2)$ & $75.45(11)$ \\
$\mathrm{N}(1)-\mathrm{Fe}(1)-\mathrm{N}(3)$ & $88.63(10)$ & $\mathrm{N}(1)-\mathrm{Fe}(1)-\mathrm{N}(4)$ & $82.32(10)$ \\
$\mathrm{N}(2)-\mathrm{Fe}(1)-\mathrm{N}(3)$ & $161.61(11)$ & $\mathrm{N}(2)-\mathrm{Fe}(1)-\mathrm{N}(4)$ & $92.37(10)$ \\
$\mathrm{N}(3)-\mathrm{Fe}(1)-\mathrm{N}(4)$ & $76.16(10)$ & $\mathrm{Cl}(2)-\mathrm{Fe}(2)-\mathrm{O}(1)$ & $101.91(8)$ \\
$\mathrm{Cl}(2)-\mathrm{Fe}(2)-\mathrm{N}(5)$ & $86.96(8)$ & $\mathrm{Cl}(2)-\mathrm{Fe}(2)-\mathrm{N}(6)$ & $95.77(9)$ \\
$\mathrm{Cl}(2)-\mathrm{Fe}(2)-\mathrm{N}(7)$ & $162.27(8)$ & $\mathrm{Cl}(2)-\mathrm{Fe}(2)-\mathrm{N}(8)$ & $93.54(8)$ \\
$\mathrm{O}(1)-\mathrm{Fe}(2)-\mathrm{N}(5)$ & $166.51(11)$ & $\mathrm{O}(1)-\mathrm{Fe}(2)-\mathrm{N}(6)$ & $94.16(11)$ \\
$\mathrm{O}(1)-\mathrm{Fe}(2)-\mathrm{N}(7)$ & $94.29(11)$ & $\mathrm{O}(1)-\mathrm{Fe}(2)-\mathrm{N}(8)$ & $102.05(11)$ \\
$\mathrm{N}(5)-\mathrm{Fe}(2)-\mathrm{N}(6)$ & $74.67(11)$ & $\mathrm{N}(5)-\mathrm{Fe}(2)-\mathrm{N}(7)$ & $78.49(11)$ \\
$\mathrm{N}(5)-\mathrm{Fe}(2)-\mathrm{N}(8)$ & $87.34(11)$ & $\mathrm{N}(6)-\mathrm{Fe}(2)-\mathrm{N}(7)$ & $90.14(11)$ \\
$\mathrm{N}(6)-\mathrm{Fe}(2)-\mathrm{N}(8)$ & $159.21(11)$ & $\mathrm{N}(7)-\mathrm{Fe}(2)-\mathrm{N}(8)$ & $75.87(11)$ \\
$\mathrm{Fe}(1)-\mathrm{O}(1)-\mathrm{Fe}(2)$ & $165.87(15)$ & & \\
\hline
\end{tabular}

\subsection{Magnetic Properties of Complexes, 1, 2, and $\mathbf{3}$}

The cryomagnetic behaviors for complexes 1, 2, and 3 were quite similar to each other, and the $\chi_{\mathrm{M}} T$ versus $T$ plots for 1, 2, and $\mathbf{3}$ are shown in Figure 4 and Figures S4 and S5, respectively. For 1 , the observed $\chi_{\mathrm{M}} T$ value at $300 \mathrm{~K}$ was $0.860 \mathrm{~cm}^{3} \cdot \mathrm{K} \cdot \mathrm{mol}^{-1}$, and the $\chi_{\mathrm{M}} T$ product linearly decreased on cooling to $\sim 80 \mathrm{~K}\left(0.089 \mathrm{~cm}^{3} \cdot \mathrm{K} \cdot \mathrm{mol}^{-1}\right)$, suggesting a strong antiferromagnetic interaction between the two iron(III) centers. Actually, the magnetic data in the temperature range of 1.9-300 K could be fitted in both high- and low-spin states; however, the magnetic similarity of $\mathbf{1}, \mathbf{2}$, and 3 can be reasonably explained by assuming the high-spin state. If in the low-spin state, the ground term was ${ }^{2} T_{2}$, possessing the orbital angular momentum, and the magnetic behavior must be sensitive to the symmetry around the iron(III) ion due to the spin-orbit coupling; the low-temperature data could be fitted with a similar large anisotropic interaction, which is not reasonable. On the contrary, if in the high-spin state, the ground term was ${ }^{6} A_{1}$, which is less sensitive to the symmetry, and the low-temperature data were successfully interpreted by a very small amount of paramagnetic impurity, $\rho$. Therefore, the magnetic simulation was conducted with the following equation (Equation (1)) with $x=J /(k T)$, assuming the isotropic exchange interaction with the Hamiltonian $\mathbf{H}=-J \mathbf{S}_{1} \cdot \mathbf{S}_{2}\left(S_{1}=S_{2}=5 / 2\right)$, where $\rho$ is the paramagnetic impurity with $S=5 / 2$.

$$
\chi_{\mathrm{M}}=2\left(\frac{N g^{2} \beta^{2}}{k T} \frac{e^{x}+5 e^{3 x}+14 e^{6 x}+30 e^{10 x}+55 e^{15 x}}{1+3 e^{x}+5 e^{3 x}+7 e^{6 x}+9 e^{10 x}+11 e^{15 x}}+\mathrm{TIP}\right)(1-\rho)+2\left(\frac{35 N g^{2} \beta^{2}}{12 k T}+\mathrm{TIP}\right) \rho
$$




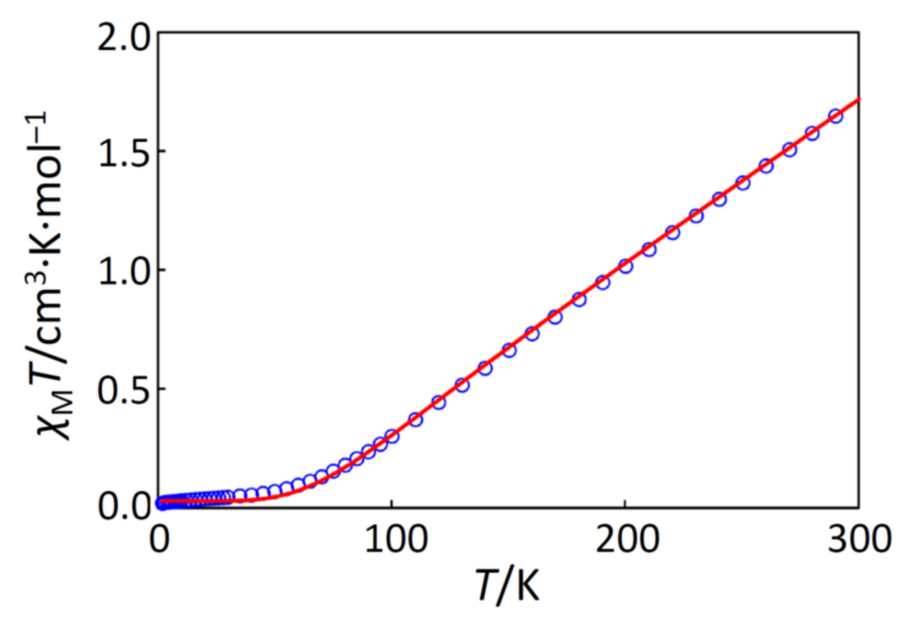

Figure 4. The $\chi_{\mathrm{M}}$ T versus $T$ plot for 1 . The observed data $(\bigcirc)$ and the theoretical curve (-) with the best-fitting parameter set $(J, g, \mathrm{TIP}, \rho)=\left(-205 \mathrm{~cm}^{-1}, 2.00,0 \mathrm{~cm}^{3} \cdot \mathrm{mol}^{-1}, 0.0017\right)$.

The best-fitting parameter set was obtained as $(J, g, \mathrm{TIP}, \rho)=\left(-205 \mathrm{~cm}^{-1}, 2.00,0 \mathrm{~cm}^{3} \cdot \mathrm{mol}^{-1}\right.$, 0.0017 ) with a good discrepancy factor of $R\left(\chi_{\mathrm{M}} T\right)=2.8 \times 10^{-4}$. In the data fitting, the $g$-factor and TIP (temperature-independent paramagnetism) were fixed to 2.00 and $0 \mathrm{~cm}^{3} \cdot \mathrm{mol}^{-1}$, respectively, because the iron(III) center has the high-spin $d^{5}$ electronic configuration. In the same way, the cryomagnetic data for $\mathbf{2}$ and $\mathbf{3}$ were successfully fitted with similar magnetic parameters as summarized in Table 7.

Table 7. Magnetic parameters of the present complexes.

\begin{tabular}{cccc}
\hline Complex & $\mathbf{1}$ & $\mathbf{2}$ & $\mathbf{3}$ \\
\hline$J / \mathrm{cm}^{-1}$ & -205 & -205 & -207 \\
$g($ fixed $)$ & 2.00 & 2.00 & 2.00 \\
$\mathrm{TIP} / \mathrm{cm}^{3} \cdot \mathrm{mol}^{-1}$ (fixed) & 0 & 0 & 0 \\
$\rho$ & 0.0017 & 0.0011 & 0.0035 \\
\hline
\end{tabular}

The obtained magnetic interaction parameters, $J$, were very similar to each other for complexes 1, 2, and 3. With the intension of finding a magnetostructural correlation, the $J$ values were plotted against the $\mathrm{Fe} \cdots$ Fe distances and the $\mathrm{Fe}-\mathrm{O}-\mathrm{Fe}$ angles with other oxido-bridged dinuclear iron(III) complexes [6,20] (Figure 5). It is noted that the reported values using the different Hamiltonian were corrected for the Hamiltonian $\mathbf{H}=-J \mathbf{S}_{1} \cdot \mathbf{S}_{2}$. The $J$ values were found to fall in the range of $-160--265 \mathrm{~cm}^{-1}$ for the oxido-bridged dinuclear iron(III) complexes. In addition, their Fe...Fe distances and Fe-O-Fe angles fell in the ranges of 3.04-3.60 $\AA$ and $113-180^{\circ}$, respectively. Although the typical ranges were found for the oxido-bridged dinuclear iron(III) complexes, further correlation was not found.

Since the symmetry of the complex cations in 1,2 , and 3 was $C_{2}$ or pseudo- $C_{2}$, the Dzyaloshinskii-Moriya interaction was expected to occur; however, we concluded that the Dzyaloshinskii-Moriya interaction was negligible in the magnetic data of $\mathbf{1}, \mathbf{2}$, and $\mathbf{3}$ obtained in this study. This may be due to the isotropic ${ }^{6} A_{1}$ ground state.

\subsection{Electronic Spectra of Complexes, 1, 2, and 3}

The electronic spectra of complexes 1, 2, and $\mathbf{3}$ were measured in acetonitrile. Judging from the molar conductance in acetonitrile (see Section 3.3), the complexes were found to act as 2:1 electrolytes in acetonitrile [21], indicating that the dinuclear iron(III) units are stable in acetonitrile. The spectra are shown in Figure 6, and the analyzed spectral components are summarized in Table 8. Each complex shows a weak band in the near-infra-red region, several bands in the visible region, and two intense bands in the near-ultraviolet region. These features were similar to those reported for the related oxido-bridged dinuclear 
iron(III) complexes [14]. If complexes $\mathbf{1}, \mathbf{2}$, and $\mathbf{3}$ were compared, $\mathbf{1}$ and $\mathbf{3}$ were similar below $20,000 \mathrm{~cm}^{-1}$, while 1 and 2 were similar above $20,000 \mathrm{~cm}^{-1}$. Remembering the structural features, both $\mathbf{1}$ and 3 have the $\mathrm{ClN}_{4} \mathrm{O}$ coordination geometry, but 2 has the $\mathrm{N}_{4} \mathrm{O}_{2}$ coordination geometry. On the other hand, $\mathbf{1}$ and $\mathbf{2}$ have the bpy ligands, but $\mathbf{3}$ has the phen ligands. Judging from the spectral similarity between $\mathbf{1}$ and $\mathbf{3}$, possessing the same $\mathrm{ClN}_{4} \mathrm{O}$ coordination geometry, the bands at around 10,000 $\mathrm{cm}^{-1}$ (components 1 and 2 in Table 8 ) are related to the coordination geometries around the iron(III) ions. Since the band intensity of $\mathbf{2}$ was larger than the others, the ligand-field symmetry around the iron(III) ion in $\mathbf{2}$ is expected to be lower than the others. That is, the intensity of the Laporte-forbidden $\mathrm{d}-\mathrm{d}$ band becomes stronger when the symmetry lowers to make the Laporte forbidden relaxed. This is consistent with the larger distortion of $\mathbf{2}$ than those of the others, judging from the crystal structures (see Section 2.2). The bands in the range of $17,000-25,000 \mathrm{~cm}^{-1}$ are common to $1,2,3$, and other related oxido-bridged iron(III) compounds, and bands are related to the typical red color of the oxido-iron(III) bonds. Above $30,000 \mathrm{~cm}^{-1}$, since 1 and 2 were similar, the bands are expected to be more related to the bidentate ligands.

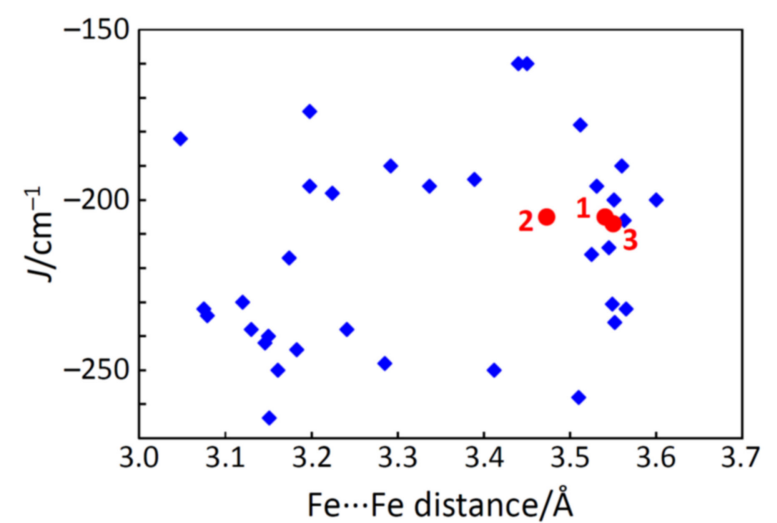

(a)

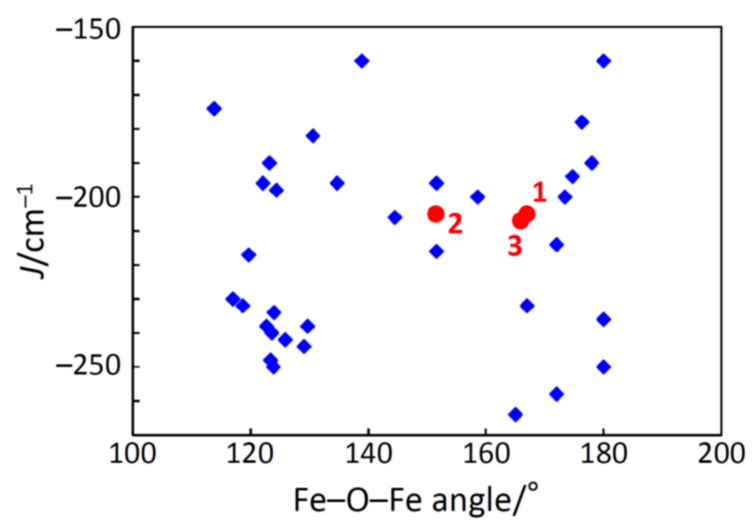

(b)

Figure 5. Plots of interaction parameter J versus Fe $\cdots$ Fe distances (a) and versus Fe-O-Fe angles (b) for complexes 1-3 (•) and related oxido-bridged dinuclear iron(III) complexes $(\diamond)$.

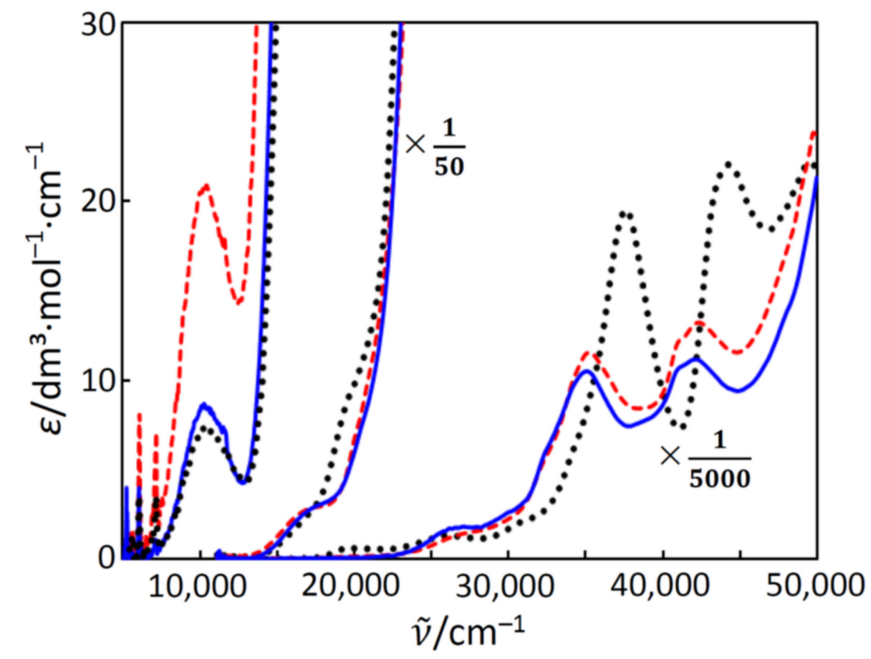

Figure 6. Electronic spectra of $\mathbf{1}(-), \mathbf{2}(-)$, and $\mathbf{3}(\cdots)$ in acetonitrile. 
Table 8. Spectral components $\left(\mathrm{cm}^{-1}\right)$ for 1,2 , and $3 .^{1}$

\begin{tabular}{cccc}
\hline Component & $\mathbf{1}$ & $\mathbf{2}$ & $\mathbf{3}$ \\
\hline 1 & $9410(3.74)$ & $9870(18.4)$ & $9370(2.21)$ \\
2 & $11,000(7.53)$ & $12,100(11.4)$ & $10,900(6.78)$ \\
3 & $16,400(87.9)$ & $16,100(171)$ & $17,200(91.5)$ \\
4 & $18,500(103)$ & $17,800(179)$ & $19,000(88.0)$ \\
5 & $21,400(320)$ & $20,900(683)$ & $20,200(438)$ \\
6 & & $23,700(683)$ & \\
7 & $25,800(3940)$ & $26,300(2370)$ & $25,300(5150)$ \\
8 & $30,100(10,800)$ & $31,000(10,600)$ & $30,700(5020)$ \\
9 & $32,300(2680)$ & $32,200(4410)$ & $34,500(24,100)$ \\
10 & $35,200(49,600)$ & $35,500(53,800)$ & $37,700(92,400)$ \\
11 & $39,100(28,300)$ & $39,100(28,900)$ & \\
& $40,800(14,700)$ & $40,800(17,700)$ & $44,200(110,000)$ \\
\hline
\end{tabular}

${ }^{1}$ Molar absorption coefficients $\left(\mathrm{dm}^{3} \cdot \mathrm{mol}^{-1} \cdot \mathrm{cm}^{-1}\right)$ are in parentheses.

In order to assign the observed components in electronic spectra, spectral simulation was conducted on the basis of the ligand field theory using the angular overlap model (AOM) [22]. For each complex, spectral components 1, 2, and 3 were simulated for the highspin $(S=5 / 2)$ state and for the low-spin $(S=1 / 2)$ state, assuming the ideal $O$ symmetry, and the results are summarized in Tables 9 and 10, respectively. Using the Racah parameters, $B$ and $C$, and the average AOM parameter, $e_{\sigma, \text { av }}$, the spectral components were simulated in both spin states; however, the obtained Racah parameters were abnormal in the low-spin state, especially for complex 2. Assuming the high-spin state, all of the obtained parameters were normal, and $B$ and $C$ fell in the ranges of $78 \%-94 \%$ and $70 \%-83 \%$ of the free-ion values (1029 and $4200 \mathrm{~cm}^{-1}$ ), respectively. According to the simulation, components 1 and 2 were assigned to ${ }^{6} A_{1} \rightarrow{ }^{2} T_{2}$ and ${ }^{6} A_{1} \rightarrow{ }^{4} T_{1}$ bands, respectively, and these assignments were consistent with the earlier studies on $\mu$-oxido- $\mu$-carboxylatodiiron(III) complexes [23,24].

Table 9. Angular overlap model simulation assuming the high-spin state.

\begin{tabular}{cccc}
\hline Parameter/Term & $\mathbf{1}$ & $\mathbf{2}$ & $\mathbf{3}$ \\
\hline$B$ & 804 & 867 & 966 \\
$C$ & 3500 & 3500 & 2940 \\
$e_{\sigma, \text { av }}$ & 5790 & 5960 & 5200 \\
\hline${ }^{6} A_{1}$ & 0 & 0 & 0 \\
${ }^{2} T_{2}$ & 9410 & 9870 & 9370 \\
${ }^{4} T_{1}$ & 11,000 & 12,100 & 10,900 \\
${ }^{4} T_{2}$ & 16,400 & 16,100 & 17,200 \\
${ }^{2} A_{2}$ & 23,100 & 28,400 & 21,600 \\
${ }^{2} T_{1}$ & 23,400 & 28,500 & 22,000 \\
${ }^{2} T_{2}$ & 25,100 & 30,100 & 23,800 \\
${ }^{4} A_{1}$ & 25,600 & 30,900 & 24,400 \\
${ }^{2} E$ & 27,000 & 32,000 & 25,600 \\
${ }^{4} T_{2}$ & 28,300 & 32,700 & 28,000 \\
${ }^{4} E$ & 31,200 & 35,000 & 31,100 \\
${ }^{2} T_{1}$ & 32,000 & 35,600 & 31,300 \\
\hline
\end{tabular}

${ }^{1}$ The $\pi$ orbital effect was not considered. 
Table 10. Angular overlap model simulation assuming the low-spin state.

\begin{tabular}{cccc}
\hline Parameter/Term & $\mathbf{1}$ & $\mathbf{2}$ & $\mathbf{3}$ \\
\hline$B$ & 739 & 547 & 864 \\
$C$ & 3830 & $5220^{2}$ & 3390 \\
$e_{\sigma, \text { av }}{ }^{1}$ & 9440 & 11400 & 8980 \\
\hline${ }^{2} T_{2}$ & 0 & 0 & 0 \\
${ }^{6} A_{1}$ & 9410 & 9870 & 9370 \\
${ }^{4} T_{1}$ & 11,000 & 12,100 & 10,900 \\
${ }^{4} T_{2}$ & 16,400 & 16,100 & 17,200 \\
${ }^{2} A_{2}$ & 24,000 & 28,900 & 22,800 \\
${ }^{2} T_{1}$ & 24,300 & 29,100 & 23,100 \\
${ }^{2} T_{2}$ & 26,200 & 30,700 & 25,300 \\
\hline
\end{tabular}

${ }^{1}$ The $\pi$ orbital effect was not considered. ${ }^{2}$ The value is abnormal compared with the free-ion value.

The intensity of spectral components 3 and 4 in Table 8 was stronger than those of the standard d-d transition bands, but as suggested earlier [14], the intensity of the components is considered to be enhanced by the energetically close strong charge-transfer band(s). Based on the simulation in this study, components 3 and 4 were considered to be based on the ${ }^{6} A_{1} \rightarrow{ }^{4} T_{1}$ band typically enhanced by the oxido ligand, which was consistent with earlier studies $[23,24]$. The absorption bands higher in energy could not be assigned in detail using the ideal octahedral model.

\subsection{Factors in Controlling the Structures}

Complex cations in 1, 2, and 3 were $C_{2}$ or pseudo- $C_{2}$ symmetry, possessing the bent $\mathrm{Fe}-\mathrm{O}-\mathrm{Fe}$ bridge. However, some of the oxido-bridged dinuclear iron(III) complexes are centrosymmetric ( $C_{i}$ symmetry), possessing the linear $\mathrm{Fe}-\mathrm{O}-\mathrm{Fe}$ bridge $[5,7,8]$. To avoid the intramolecular steric repulsions between ligands, the centrosymmetric structures are generally preferable; on the other hand, if the two protons of water molecules are replaced with iron(III) ions, the bent bridging structures are considered to be natural. In order to find the factors for controlling the structures, we examined the effects of intramolecular interactions in this section.

In the $\mathrm{C}_{2}$-symmetric complex cations, the intramolecular $\mathrm{CH} \cdots \mathrm{O}$ hydrogen bonds were observed between the bpy and oxido ligands. In addition, the intramolecular $\mathrm{CH} \cdots \mathrm{Cl}$ or $\mathrm{CH} \cdots \mathrm{O}$ hydrogen bonds were observed between the bpy (or phen) moiety on an iron(III) ion and the anion ligand moiety on another iron(III) ion. These attractive interactions are helpful in fixing the structure in a certain structure. For example, the intramolecular interligand hydrogen bonds are shown for $\left[\mathrm{Fe}_{2} \mathrm{OCl}_{2}(\mathrm{bpy})_{4}\right]^{2+}$ in Figure $7 \mathrm{a}$. The dihedral angles of $\mathrm{Cl}-\mathrm{Fe} \cdots \mathrm{Fe}-\mathrm{Cl}$ were $107^{\circ}$ in $\mathbf{1}$ and $79^{\circ}$ in 3 , and the dihedral angle of $\mathrm{O}$ (nitrato)$\mathrm{Fe} \cdots \mathrm{Fe}-\mathrm{O}$ (nitrato) was $131^{\circ}$. In each structure, the dihedral angle seems to be fixed to the most stable structure balancing the intramolecular interactions and the intramolecular steric repulsions. In order to check this, for example, energy calculation was conducted on the basis of the density functional theory (DFT) with respect to the dihedral angles in $\mathbf{1}$.

The resulting energy values for $\left[\mathrm{Fe}_{2} \mathrm{OCl}_{2}(\mathrm{bpy})_{4}\right]^{2+}$ in 1 were plotted as the energy differences from the most stable energy value in Figure $8 \mathrm{a}$ on the basis of the $C_{i}$ structure and of the $C_{2}$ structure. The energy minimum for the $C_{2}$ structure was found to be more stable than that for the $C_{i}$ structure. The energy minimum was observed at around a dihedral angle of $\sim 130^{\circ}$, which was slightly larger than that in the crystal structure $\left(107^{\circ}\right)$. This difference is thought to be caused by the intermolecular interactions, including the $\mathrm{CH} \cdots \mathrm{Cl}$ interaction between the cations and the $\mathrm{CH} \cdots \mathrm{F}$ interaction between the cation and anion, observed in the crystal structure. Anyway, the most important factor in controlling the structure was found to be the intramolecular interligand interactions. 


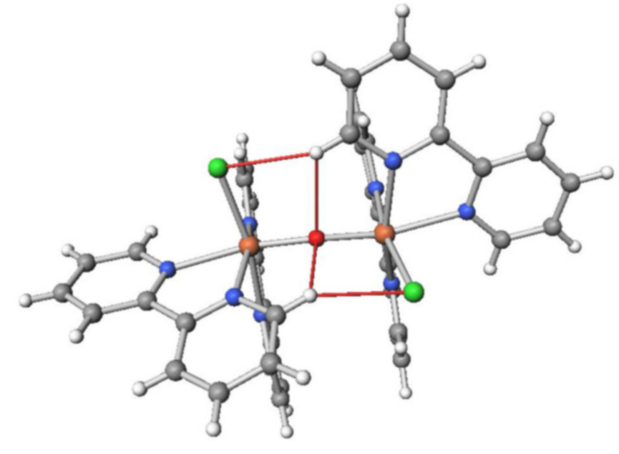

(a)

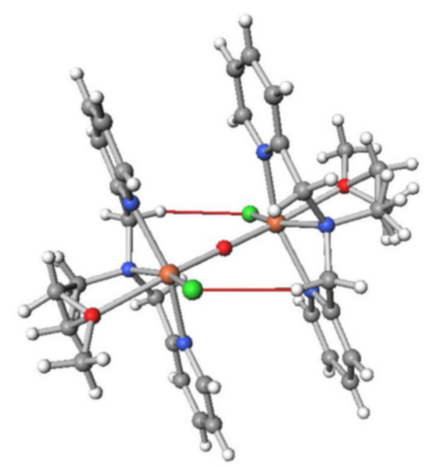

(b)

Figure 7. Intramolecular interligand hydrogen bonds in oxido-bridged dinuclear iron(III) complex cations: (a) $C_{2}$-symmetric $\left[\mathrm{Fe}_{2} \mathrm{OCl}_{2}(\text { bpy })_{4}\right]^{2+}$; (b) $C_{i}$-symmetric $\left[\mathrm{Fe}_{2} \mathrm{OCl}_{2}(\text { epy })_{4}\right]^{2+}$. Significant hydrogen bonds are shown in red.

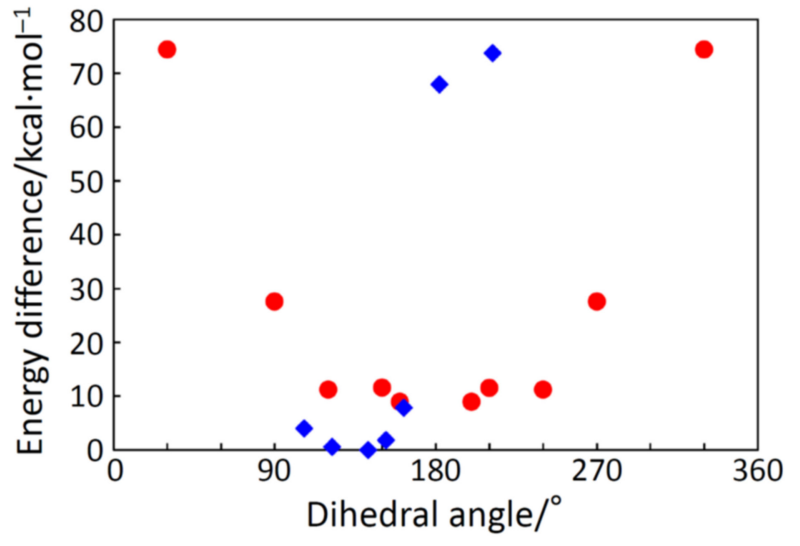

(a)

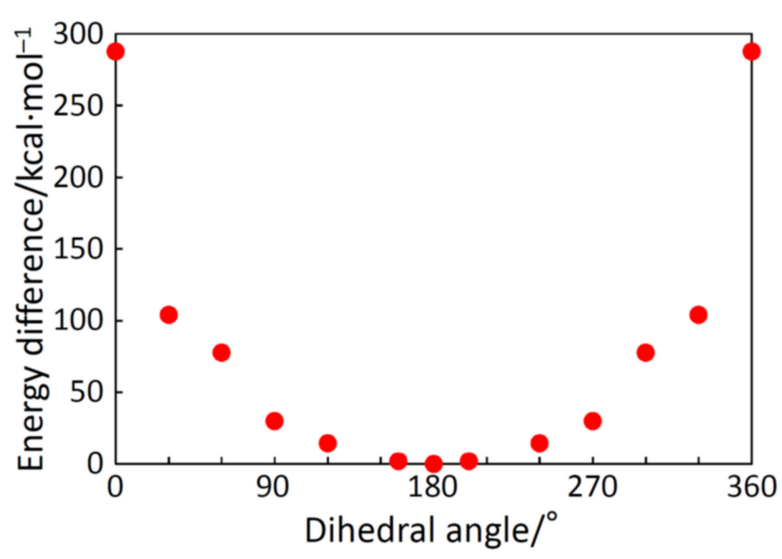

(b)

Figure 8. Energy change with respect to the $\mathrm{Cl}-\mathrm{Fe} \cdots \mathrm{Fe}-\mathrm{Cl}$ dihedral angle for $\left[\mathrm{Fe}_{2} \mathrm{OCl}_{2}(\mathrm{bpy})_{4}\right]^{2+}(\mathbf{a})$ and $\left[\mathrm{Fe}_{2} \mathrm{OCl} \mathrm{Ol}_{2}(\mathrm{epy})_{4}\right]^{2+}$ (b) on the basis of the $C_{i}$ structure $(\bullet)$ and the $C_{2}$ structure $(\diamond)$.

Another calculation example was the $C_{i}$-symmetric oxido-bridged dinuclear iron(III) complex cation with a tetradentate ligand, $\mathrm{N}$-(2-methoxyethyl)- $\mathrm{N}, \mathrm{N}$-bis(pyridin-2-ylmethyl) amine (epy), $\left[\mathrm{Fe}_{2} \mathrm{OCl}_{2}(\text { epy })_{2}\right]^{2+}[5,7]$ (Figure $7 \mathrm{~b}$ ), and the angle dependency is shown in Figure $8 \mathrm{~b}$. The structure of this cation was centrosymmetric, and the dihedral angle of $\mathrm{Cl}-\mathrm{Fe} \cdots \mathrm{Fe}-\mathrm{Cl}$ was $180^{\circ}$. In the crystal structure, the apparent $\mathrm{CH} \cdots \mathrm{Cl}$ hydrogen bonds exist between the methylene chain and the chloride ligand, and the hydrogen bonds seem to stabilize the centrosymmetric structure (Figure $7 \mathrm{~b}$ ). In the dihedral angle rotation calculation, a dihedral angle of $180^{\circ}$ was found to be the most stable, which was consistent with the crystal structure. Furthermore, other conformations looked no longer preferable due to the interligand steric repulsion. Therefore, the most important factor in controlling the structure was again found to be the intramolecular interligand interactions.

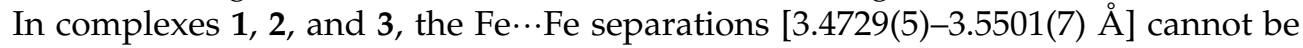
so smaller than the $\pi-\pi$ contact, discussed in Section 2.2, judging from the structures. This is a strict barrier caused by the steric requirement. In natural ores, goethite [2] and hematite [25], the effect of the interligand steric repulsion is much smaller because of their small sizes, and their Fe $\cdots$ Fe separations are smaller $[\sim 3.01 \AA$ and $\sim 2.90 \AA$, respectively] as expected. Therefore, we can conclude that the $\mathrm{Fe}-\mathrm{O}-\mathrm{Fe}$ bridge tends to bend like a water molecule, but is often stretched by interligand steric repulsion. A good correlation was observed between the $\mathrm{Fe} \cdots \mathrm{Fe}$ distance and $\mathrm{Fe}-\mathrm{O}-\mathrm{Fe}$ angle, as shown in Figure 9. 


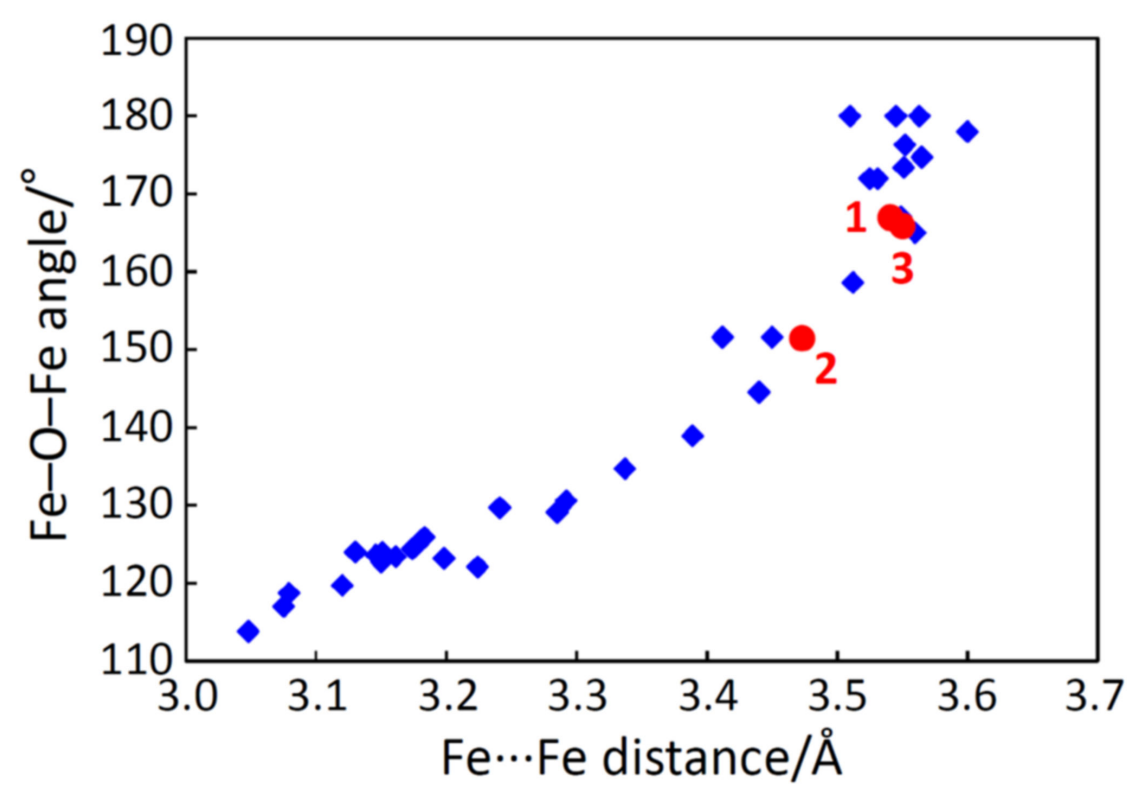

Figure 9. Plots of $\mathrm{Fe}-\mathrm{O}-\mathrm{Fe}$ angles versus $\mathrm{Fe} \cdots \mathrm{Fe}$ distances for complexes $\mathbf{1 - 3}(\bullet)$ and related oxidobridged dinuclear iron(III) complexes $(\diamond)$.

\section{Materials and Methods}

\subsection{Measurements}

Elemental analyses $(\mathrm{C}, \mathrm{H}$, and $\mathrm{N})$ were performed at the Elemental Analysis Service Centre of Kyushu University. Iron(III) ions were quantified by titration with ethylenediaminetetraacetic acid in the presence of hydrochloric acid, using variamine blue B as an indicator. IR spectra were recorded on a Jasco FT/IR-4100 FT-IR spectrometer. Electronic spectra were measured at room temperature on Jasco V-560 (200-800 nm) and Hitachi 330 (800-2000 nm) spectrophotometers. Molar conductances were measured in $\mathrm{MeOH}$ on a DKK AOL-10 conductivity meter at room temperature. Magnetic susceptibility measurements were performed with a Quantum Design MPMS-7 SQUID magnetometer in the temperature range from 1.9 to $300 \mathrm{~K}$ with a static field of $5 \mathrm{kOe}$. The polycrystalline samples were ground into fine powders in an agate mortar. The sample was wrapped with aluminum foil for $\mathbf{1}$ and $\mathbf{2}$. The sample for $\mathbf{3}$ was loaded into a gelatin capsule. All data were corrected for paramagnetism of the aluminum foil or diamagnetism of the capsule. The susceptibilities were corrected for the diamagnetism of the samples by means of Pascal's constants.

\subsection{Materials}

All the chemicals were commercial products and were used as supplied. Methanol, iron(III) nitrate-water (1/9), iron(III) chloride-water (1/6), 2,2'-bipyridine, acetonitrile, 2-propanol, 1,10-phenanthroline, ethylenediaminetetraacetic acid, and hydrochloric acid were supplied by Nacalai Tesque Inc. Sodium hexafluoridophosphate and variamine blue B were supplied by FUJIFILM Wako Pure Chemical Corporation.

\subsection{Preparations}

$\left[\mathrm{Fe}_{2} \mathrm{OCl}_{2}(\mathrm{bpy})_{4}\right]\left[\mathrm{PF}_{6}\right]_{2}$ 1. All operations were conducted in the dark. To a methanolic solution $(10 \mathrm{~mL})$ of iron(III) nitrate-water $(1 / 9)(0.54 \mathrm{~g}, 1.3 \mathrm{mmol})$ was added a methanolic solution $(5 \mathrm{~mL})$ of iron(III) chloride-water $(1 / 6)(0.18 \mathrm{~g}, 0.66 \mathrm{mmol})$ and a methanolic solution $(5 \mathrm{~mL})$ of $2,2^{\prime}$-bipyridine $(0.62 \mathrm{~g}, 4.0 \mathrm{mmol})$, and the resulting solution was stirred for 120 min to give a dark-yellow solution. The addition of sodium hexafluoridophosphate $(0.40 \mathrm{~g}, 2.4 \mathrm{mmol})$ resulted in the precipitation of dark-yellow powder. Recrystallized from acetonitrile/2-propanol to give dark-yellow powder. Yield: $0.40 \mathrm{~g}$ (36\%) (found: C, 42.90; $\mathrm{H}, 3.10 ; \mathrm{N}, 10.20$; Fe, 10.00; calc. for $\mathrm{C}_{40} \mathrm{H}_{32} \mathrm{Cl}_{2} \mathrm{~F}_{12} \mathrm{Fe}_{2} \mathrm{~N}_{8} \mathrm{OP} 2$ : C, 43.15; H, 2.90; N, 10.05; Fe, 
10.05). Selected IR data $\left[\tilde{v} / \mathrm{cm}^{-1}\right]$ using KBr disk: 3130-3025, 1600, 1445, 1315, 1160, 1025 , 840, 770, 560. Molar conductance in MeCN $\left[\Lambda / \mathrm{S} \mathrm{cm}^{2} \cdot \mathrm{mol}^{-1}\right] 232$.

$\left[\mathrm{Fe}_{2} \mathrm{O}\left(\mathrm{NO}_{3}\right)_{2}(\mathrm{bpy})_{4}\right]\left[\mathrm{PF}_{6}\right]_{2} \cdot 0.6 \mathrm{MeCN} \cdot 0.2(2-\mathrm{PrOH}) 2$. All operations were conducted in the dark. To a methanolic solution $(10 \mathrm{~mL})$ of iron(III) nitrate-water $(1 / 9)(0.81 \mathrm{~g}$, $2.0 \mathrm{mmol})$ was added a methanolic solution $(5 \mathrm{~mL})$ of 2,2'-bipyridine $(0.62 \mathrm{~g}, 4.0 \mathrm{mmol})$, and the resulting solution was stirred for $120 \mathrm{~min}$ to give a dark-brown solution. The addition of sodium hexafluoridophosphate $(0.40 \mathrm{~g}, 2.4 \mathrm{mmol})$ resulted in the precipitation of dark-brown powder. Recrystallized from acetonitrile/2-propanol to give darkbrown powder. Yield: $0.60 \mathrm{~g}(52 \%)$ (found: $\mathrm{C}, 41.85 ; \mathrm{H}, 2.95 ; \mathrm{N}, 12.45 ; \mathrm{Fe}, 9.10$; calc. for $\mathrm{C}_{41.8} \mathrm{H}_{35.4} \mathrm{~F}_{12} \mathrm{Fe}_{2} \mathrm{~N}_{10.6} \mathrm{O}_{7.2} \mathrm{P}_{2}$ : C, 41.75; H, 2.95; N, 12.35; Fe, 9.30). Selected IR data $\left[\tilde{v} / \mathrm{cm}^{-1}\right]$ using $\mathrm{KBr}$ disk: 3170-3010, 1600, 1445, 1380, 1280, 1165, 1030, 840, 770, 560. Molar conductance in $\mathrm{MeCN}\left[\Lambda / \mathrm{S} \mathrm{cm}^{2} \cdot \mathrm{mol}^{-1}\right] 244$.

$\left.\left[\mathrm{Fe}_{2} \mathrm{OCl}_{2} \text { (phen }\right)_{4}\right]\left[\mathrm{PF}_{6}\right]_{2} \cdot \mathrm{MeCN} \cdot 0.5 \mathrm{H}_{2} \mathrm{O} 3$. All operations were conducted in the dark. To a methanolic solution $(10 \mathrm{~mL})$ of iron(III) chloride-water $(1 / 6)(0.27 \mathrm{~g}, 1.0 \mathrm{mmol})$ was added a methanolic solution $(5 \mathrm{~mL})$ of 1,10-phenanthroline $(0.40 \mathrm{~g}, 2.0 \mathrm{mmol})$, and the resulting solution was stirred for $120 \mathrm{~min}$ to give a dark-brown solution. After filtration, the addition of sodium hexafluoridophosphate $(0.20 \mathrm{~g}, 1.2 \mathrm{mmol})$ resulted in the precipitation of dark-brown powder. Recrystallized from acetonitrile/2-propanol to give dark-brown powder. Yield: $0.21 \mathrm{~g}(35 \%)$ (found: C, 47.25; H, 2.80; N, $9.10 \mathrm{Fe}, 9.05$; calc. for $\mathrm{C}_{48} \mathrm{H}_{33} \mathrm{Cl}_{2} \mathrm{~F}_{12} \mathrm{Fe}_{2} \mathrm{~N}_{8} \mathrm{O}_{1.5} \mathrm{P}_{2}(3-\mathrm{MeCN})$ : $\left.\mathrm{C}, 47.32 ; \mathrm{H}, 2.73 ; \mathrm{N}, 9.20 ; \mathrm{Fe}, 9.15\right)$. Selected IR data $\left[\tilde{v} / \mathrm{cm}^{-1}\right.$ ] using $\mathrm{KBr}$ disk: 3165-2980, 1585-1630, 1520, 1150, 1105, 840, 725, 560. Molar conductance in $\mathrm{MeCN}\left[\Lambda / \mathrm{S} \mathrm{cm}^{2} \cdot \mathrm{mol}^{-1}\right] 258$.

\subsection{Crystallography}

Crystallographic data are summarized in Table 11. Single crystals of $\mathbf{1}$ and $\mathbf{2}$ suitable for X-ray analysis were obtained by slow diffusion of 2-propanol to an acetonitrile solution of the complexes. Single crystals of 3 were obtained from an acetonitrile solution of 3 . Singlecrystal X-ray diffraction data were obtained with a Bruker SMART APEX or Rigaku XtaLAB AFC11 diffractometer with graphite-monochromated Mo K $\alpha$ radiation $(\lambda=0.71073 \AA)$. A single crystal was mounted with a cryoloop or glass capillary and flash-cooled with a cold $\mathrm{N}_{2}$ gas stream. Data were processed using the SMART or CrysAlisPro software packages. The structure was solved by intrinsic phasing methods using the SHELXT [26] software packages and refined on $F^{2}$ (with all independent reflections) using the SHELXL [27] software packages. The non-hydrogen atoms were refined anisotropically, and hydrogen atoms were refined using the riding model. Complex 2 was refined as a two-component twin. The Cambridge Crystallographic Data Centre (CCDC) deposition numbers are included in Table 11.

\subsection{Computation}

Magnetic analyses and magnetic simulation were conducted using the MagSaki(FeIII) 0.0.4 and MagSaki(B)0.7.5 programs of the MagSaki series. AOM calculations were performed using the AOMX program on an Intel Celeron computer. DFT computations were performed using the GAMESS program [28,29] on Fujitsu PRIMERGY CX2550/CX2560 M4 (ITO super computer system) at Kyushu University. Calculations were performed with LC-BOP/6-31G [30]. 
Table 11. Crystallographic data and refinement parameters of 1, 2, and 3 .

\begin{tabular}{|c|c|c|c|}
\hline Complex & 1 & 2 & 3 \\
\hline Empirical formula & $\mathrm{C}_{40} \mathrm{H}_{32} \mathrm{Cl}_{2} \mathrm{~F}_{12} \mathrm{Fe}_{2} \mathrm{~N}_{8} \mathrm{OP}_{2}$ & $\mathrm{C}_{41.8} \mathrm{H}_{35.4} \mathrm{~F}_{12} \mathrm{Fe}_{2} \mathrm{~N}_{10.6} \mathrm{O}_{7.2} \mathrm{P}_{2}$ & $\mathrm{C}_{50} \mathrm{H}_{36} \mathrm{C}_{12} \mathrm{~F}_{12} \mathrm{Fe}_{2} \mathrm{~N}_{9} \mathrm{O}_{1.5} \mathrm{P}_{2}$ \\
\hline Formula weight & 1113.27 & 1203.04 & 1259.42 \\
\hline Crystal system & Monoclinic & Triclinic & Triclinic \\
\hline Space group & $\mathrm{C} 2 / \mathrm{c}$ & $P \overline{1}$ & $P \overline{1}$ \\
\hline$a / \AA$ & $24.5777(8)$ & $12.7471(2)$ & $12.0156(8)$ \\
\hline$b / \AA$ & $9.6680(3)$ & $13.6863(3)$ & 13.0997(8) \\
\hline$c / \AA$ & $18.2923(5)$ & $14.9623(3)$ & $17.0918(11)$ \\
\hline$\alpha /^{\circ}$ & 90 & $75.554(2)$ & $99.7840(10)$ \\
\hline$\beta /{ }^{\circ}$ & 102.781(3) & $78.197(2)$ & $97.4510(10)$ \\
\hline$\gamma /{ }^{\circ}$ & 90 & $76.516(2)$ & $104.7590(10)$ \\
\hline$V / \AA^{3}$ & $4238.9(2)$ & $2428.25(9)$ & $2521.1(3)$ \\
\hline$Z$ & 4 & 2 & 2 \\
\hline Crystal dimensions $/ \mathrm{mm}$ & $0.125 \times 0.074 \times 0.045$ & $0.190 \times 0.180 \times 0.070$ & $0.400 \times 0.340 \times 0.220$ \\
\hline$T / K$ & 105 & 102 & 90 \\
\hline$\lambda / \AA$ & 0.71073 & 0.71073 & 0.71073 \\
\hline$\rho_{\text {calcd }} / \mathrm{g} \cdot \mathrm{cm}^{-3}$ & 1.744 & 1.645 & 1.659 \\
\hline$\mu / \mathrm{mm}^{-1}$ & 0.985 & 0.771 & 0.841 \\
\hline$F(000)$ & 2240 & 1216 & 1270 \\
\hline $2 \theta_{\max } / 0$ & 55 & 57 & 55 \\
\hline No. of reflections measured & 15,350 & 61,890 & 15,982 \\
\hline No. of independent reflections & $4853($ Rint $=0.0268)$ & $12079($ Rint $=0.0403)$ & $11291($ Rint $=0.0165)$ \\
\hline Data/restraints/parameters & $4853 / 0 / 303$ & $12,079 / 240 / 790$ & $11,291 / 0 / 783$ \\
\hline$R 1^{1}[I>2.00 \sigma(I)]$ & 0.0306 & 0.0534 & 0.0522 \\
\hline$w R 2^{2}$ (all reflections) & 0.0780 & 0.1609 & 0.1265 \\
\hline Goodness of fit indicator & 1.039 & 1.064 & 1.126 \\
\hline Highest peak, deepest hole $/ \mathrm{e} \AA^{-3}$ & $0.393,-0.334$ & $1.690,-0.634$ & $0.855,-0.496$ \\
\hline CCDC deposition number & 2052873 & 2052876 & 2052878 \\
\hline
\end{tabular}

${ }^{1} R 1=\Sigma|| \mathrm{Fo}|-| \mathrm{Fc}|| / \Sigma|\mathrm{Fo}|,{ }^{2} w R 2=\left[\Sigma\left(w\left(\mathrm{Fo}^{2}-\mathrm{Fc}^{2}\right)^{2}\right) / \Sigma w\left(\mathrm{Fo}^{2}\right)^{2}\right]^{1 / 2}$.

\section{Conclusions}

Three oxido-bridged dinuclear iron(III) complexes, 1, 2, and 3, were newly prepared, and all of them were found to have the bent $\mathrm{Fe}-\mathrm{O}-\mathrm{Fe}$ bonds. Strong antiferromagnetic interaction was observed for each complex, which is characteristic for the oxido-bridged dinuclear iron(III) complexes. Electronic spectra were examined using the angular overlap model and found to be typical of the oxido-bridged dinuclear iron(III) complexes.

A good correlation was found between the $\mathrm{Fe} \cdots \mathrm{Fe}$ distance and the $\mathrm{Fe}-\mathrm{O}-\mathrm{Fe}$ angle for the known oxido-bridged dinuclear iron(III) complexes, including 1-3. For the $\mathrm{Fe} \cdots \mathrm{Fe}$ distance, a strict barrier was found to be caused by the steric requirement of the ligands. From the crystal structure, some intramolecular interligand hydrogen bonds were found to play an important role in controlling the structures.

In this study, we have concluded that the $\mathrm{Fe}-\mathrm{O}-\mathrm{Fe}$ bridge tends to bend like a water molecule, but is often stretched by interligand steric repulsion, and that the structures are mainly controlled by the intramolecular interligand interactions.

Supplementary Materials: The following are available online. Figure S1: IR spectra of 1, Figure S2: IR spectra of 2, Figure S3: IR spectra of 3, Figure S4: The $\chi_{M} T$ versus $T$ plot for 2, Figure S5: The $\chi_{M} T$ versus $T$ plot for 3.

Author Contributions: Conceptualization, R.H. and H.S.; methodology, R.H., K.Y., R.M., T.O., and H.S.; software, H.S.; validation, T.O. and H.S.; formal analysis, R.H., K.Y., R.M., and H.S.; investigation, R.H., K.Y., R.M., and H.S.; resources, H.S.; data curation, R.H. and H.S.; writingoriginal draft preparation, R.H., R.M., and H.S.; writing-review and editing, R.M., M.M., and H.S.; visualization, R.H. and H.S.; supervision, H.S.; project administration, H.S.; funding acquisition, H.S. All authors have read and agreed to the published version of the manuscript. 
Funding: This research was funded by Japan Society for the Promotion of Science (JSPS), KAKENHI, grant number 15K05445.

Data Availability Statement: The crystallographic data are available from the Cambridge Crystallographic Data Centre (CCDC). Other data not presented in Supplementary Materials are available on request from the corresponding author.

Acknowledgments: The magnetic measurements and a part of the single-crystal X-ray measurement were conducted at the Institute of Molecular Science, supported by the Nanotechnology Platform Program (Molecule and Material Synthesis). The authors thank Thomas Schönherr and Heribert Adamsky at Heinrich-Heine-Universität Düsseldorf for providing a copy of the AOMX program.

Conflicts of Interest: The authors declare no conflicts of interest. The funders had no role in the design of the study; in the collection, analyses, or interpretation of data; in the writing of the manuscript; or in the decision to publish the results.

\section{References}

1. Knight, R.J.; Sylva, R.N. Precipitation in hydrolysed iron (III) solutions. J. Inorg. Nucl. Chem. 1974, 36, 591-597. [CrossRef]

2. Gualtieri, A.F.; Venturelli, P. In situ study of the goethite-hematite phase transformation by real time synchrotron powder diffraction. Am. Mineral. 1999, 84, 895-904. [CrossRef]

3. Friesner, R.A.; Baik, M.-H.; Gherman, B.F.; Guallar, V.; Wirstam, M.; Murphy, R.B.; Lippard, S.J. How iron-containing proteins control dioxygen chemistry: A detailed atomic level description via accurate quantum chemical and mixed quantum mechanics/molecular mechanics calculations. Coord. Chem. Rev. 2003, 238-239, 267-290. [CrossRef]

4. Mizuno, R.; Kawabata, T.; Sutoh, Y.; Nishida, N.; Okada, S. Oxidative renal tubular injuries induced by aminocarboxylate-type iron (III) coordination compounds as candidate renal carcinogens. Biometals 2006, 19, 675-683. [CrossRef] [PubMed]

5. Kooijman, H.; Son, M.; Tanase, S.; Bouwman, E.; Reedijk, J.; Spek, A.L. $\mu$-Oxo-bis\{chloro[N-(2-methoxyethyl)-N,N-bis(pyridin-2ylmethyl)amine- $\left.\kappa^{4}-N_{,} N^{\prime}, N^{\prime \prime}, O\right]$ iron(III)\} bis(trifluoromethanesulfonate)acetonitrile disolvate. Acta Cryst. 2005, E61, m1042-m1044. [CrossRef]

6. Xiang, D.F.; Tan, X.S.; Zhang, S.W.; Han, Y.; Yu, K.B.; Tang, W.X. Synthesis, crystal structure and properties of $\left[\mathrm{Fe}_{2} \mathrm{O}(\mathrm{bipy})_{4} \mathrm{C1} 1_{2}\right]$ $\left(\mathrm{ClO}_{4}\right)_{2} \cdot 0.25 \mathrm{CH}_{3} \mathrm{CN} \cdot 0.25 \mathrm{CH}_{3} \mathrm{OH} \cdot 0.25 \mathrm{H}_{2} \mathrm{O}$, a $\mu$-Oxo diiron(III) complex. Polyhedron 1998, 17, 2095-2100. [CrossRef]

7. Ito, S.; Okuno, T.; Itoh, H.; Ohba, S.; Matsushima, H.; Tokii, T.; Nishida, Y. Chemical basis for high activity in oxygenation of cyclohexane catalyzed by dinuclear iron(III) complexes with ethereal oxygen containing ligand and hydrogen peroxide system. Z. Naturforsch. 1997, 52b, 719-727. [CrossRef]

8. Ito, S.; Okuno, T.; Matsushima, H.; Tokii, T.; Nishida, Y. Chemical origin of high activity in oxygenation of cyclohexane by $\mathrm{H}_{2} \mathrm{O}_{2}$ catalysed bydinuclear iron(III) complexes with amide-containing ligands. J. Chem. Soc. Dalton Trans. 1996, 4479-4484. [CrossRef]

9. Hazell, A.; Jensen, K.B.; McKenzie, C.J.; Toftlund, H. Synthesis and reactivity of ( $\mu$-oxo)diiron(III) complexes of tris(2pyridylmethyl)amine. X-ray crystal structures of $\left[\mathrm{tpa}(\mathrm{OH}) \mathrm{FeOFe}\left(\mathrm{H}_{2} \mathrm{O}\right) \mathrm{tpa}\right]\left(\mathrm{C}_{1} \mathrm{O}_{4}\right)_{3}$ and $[\mathrm{tpa}(\mathrm{Cl}) \mathrm{FeOFe}(\mathrm{Cl}) \mathrm{tpa}]\left(\mathrm{C} 1 \mathrm{O}_{4}\right)_{2}$. Inorg. Chem. 1994, 33, 3127-3134. [CrossRef]

10. Hall, S.R.; Allen, F.H.; Brown, I.D. The crystallographic information file (CIF): A new standard archive file for crystallography. Acta Cryst. 1991, A47, 655-685. [CrossRef]

11. Mukherjee, R.N.; Stack, T.D.P.; Holm, R.H. Angle dependence of the properties of the $\left[\mathrm{Fe}_{2} \mathrm{X}\right]^{4+}$ bridge unit $(\mathrm{X}=\mathrm{O}, \mathrm{S})$ : Structures, antiferromagnetic coupling, and properties in solution. J. Am. Chem. Soc. 1988, 110, 1850-1861. [CrossRef]

12. Strauss, S.H.; Pawlik, M.J.; Skowyra, J.; Kennedy, J.R.; Anderson, O.P.; Spartalian, K.; Dye, J.L. Comparison of the molecular and electronic structures of ( $\mu$-oxo)bis[(5,10,15,20-tetraphenylporphyrinato)iron(III)] and ( $\mu$-oxo)bis[(7,8-dihydro-5,10,15,20tetraphenylporphyrinato)iron(III)]. Inorg. Chem. 1987, 26, 724-730. [CrossRef]

13. Plowman, J.E.; Loehr, T.M.; Schauer, C.K.; Anderson, O.P. Crystal and molecular structure of the ( $\mu$-oxo)bis[aquobis(phenanthroline) iron(III)] complex, a Raman spectroscopic model for the binuclear iron site in hemerythrin and ribonucleotide reductase. Inorg. Chem. 1984, 23, 3553-3559. [CrossRef]

14. Reiff, W.M.; Baker, W.A., Jr.; Erickson, N.E. Binuclear, oxygen-bridged complexes of iron(III). New iron(III)-2,2' $2^{\prime \prime}$-terpyridine complexes. J. Am. Chem. Soc. 1968, 90, 4794-4800. [CrossRef]

15. Lippard, S.J.; Schugar, H.J.; Walling, C. The crystal and molecular structure of an oxo-bridged binuclear iron(III) complex, [(HEDTA)FeOFe(HEDTA)] ${ }^{2-}$. Inorg. Chem. 1967, 6, 1825-1831. [CrossRef]

16. Fleischer, E.; Hawkinson, S. The structure of two seven-coordinate complexes of iron(III). J. Am. Chem. Soc. 1967, 89, 720-721. [CrossRef]

17. Dzyaloshinsky, I. A thermodynamic theory of "weak" ferromagnetism of antiferromagnetics. J. Phys. Chem. Solids 1958, 4, 241-255. [CrossRef]

18. Moriya, T. Theory of magnetism of $\mathrm{NiF}_{2}$. Phys. Rev. 1960, 117, 635-647. [CrossRef]

19. Hoshikawa, R.; Mitsuhashi, R.; Mikuriya, M.; Sakiyama, H. Crystal structure of a mononuclear iron(II) complex, tris(1,10phenanthroline- $\left.\kappa^{2} N, N^{\prime}\right)$ iron(II) bis(hexafluoridophosphate). X-ray Struct. Anal. Online 2019, 35, 67-68. [CrossRef] 
20. Gorun, S.M.; Lippard, S.J. Magnetostructural correlations in magnetically coupled ( $\mu$-oxo)diiron(III) complexes. Inorg. Chem. 1991, 30, 1625-1630. [CrossRef]

21. Geary, W.J. The use of conductivity measurements in organic solvents for the characterisation of coordination compounds. Coord. Chem. Rev. 1971, 7, 81-122. [CrossRef]

22. Schäffer, C.E. The angular overlap model of the ligand field: Theory and applications. Pure Appl. Chem. 2009, $24,361-392$. [CrossRef]

23. Norman, R.E.; Holz, R.C.; Menage, S.; O'Connor, C.J.; Zhang, J.H.; Que, L., Jr. Structures and properties of dibridged ( $\mu-$ oxo)diiron(III) complexes. Effects of the Fe-O-Fe angle. Inorg. Chem. 1990, 29, 4629-4637. [CrossRef]

24. Reem, R.C.; McCormick, J.M.; Richardson, D.E.; Devlin, F.J.; Stephens, P.J.; Musselman, R.L.; Solomon, E.I. Spectroscopic studies of the coupled binuclear ferric active site in methemerythrins and oxyhemerythrin: The electronic structure of each iron center and the iron-oxo and iron-peroxide Bonds. J. Am. Chem. Soc. 1989, 111, 4688-4704. [CrossRef]

25. Blake, R.L.; Hessevick, R.E.; Zoltai, T.; Finger, L.W. Refinement of the hematite structure. Am. Mineral. 1966, 51, $123-129$.

26. Sheldrick, G.M. A short history of SHELX. Acta Cryst. Sect. A 2008, 64, 112-122. [CrossRef]

27. Sheldrick, G.M. Crystal structure refinement with SHELXL. Acta Cryst. Sect. C 2015, 71, 3-8. [CrossRef] [PubMed]

28. Schmidt, M.W.; Baldridge, K.K.; Boatz, J.A.; Elbert, S.T.; Gordon, M.S.; Jensen, J.H.; Koseki, S.; Matsunaga, N.; Nguyen, K.A.; $\mathrm{Su}, \mathrm{S}$.; et al. General atomic and molecular electronic structure system. J. Comput. Chem. 1993, 14, 1347-1363. [CrossRef]

29. Gordon, M.S.; Schmidt, M.W. Advances in Electronic Structure Theory; Elsevier: Amsterdam, The Netherlands, 2005.

30. Tawada, Y.; Tsuneda, T.; Yanagisawa, S.; Yanai, T.; Hirao, K. A long-range-corrected time-dependent density functional theory. J. Chem. Phys. 2004, 120, 8425-8433. [CrossRef] 